\title{
Fetal hypoxia and apoptosis following maternal porcine reproductive and respiratory syndrome virus (PRRSV) infection
}

Carolina M. Malgarin ${ }^{1}$, Fiona Moser ${ }^{1}$, J. Alex Pasternak ${ }^{1,2}$, Glenn Hamonic ${ }^{1}$, Susan E. Detmer ${ }^{1}$, Daniel J. MacPhee ${ }^{1}$ and John C. S. Harding ${ }^{1 *}$

\begin{abstract}
Background: Mechanisms of fetal death following maternal PRRSV2 infection remain uncharacterized, although hypoxia from umbilical cord lesions and/or placental detachment due to apoptosis are hypothesized. We performed two experiments examining hypoxia and apoptosis in PRRSV-infected and non-infected, third-trimester fetuses to elucidate possible associations with fetal death. Fetuses were selected based on four phenotypic infection groups: fetuses from non-challenged control gilts (CTRL); low viral load fetuses (LVL; Exp 1) or uninfected fetuses (UNINF; Exp 2) from inoculated gilts; viable high viral load fetuses (HVL-VIA); and HVL meconium-stained fetuses (HVL-MEC).

Results: In experiment 1, paraffin embedded fetal tissues collected 21 days post maternal infection (DPI) were examined for DNA fragmentation associated with apoptosis. Positively stained foci were larger and more numerous $(P<0.05)$ in heart, liver, and thymus of HVL-VIA and HVL-MEC compared to CTRL and LVL fetuses. In experiment 2, group differences in gene expression within the hypoxia (HIF1a, IDO1, VEGFa, LDHA, NOS2, NOX1) and apoptosis (CASP3, CASP7, CASP8, CASP9, RIPK1, RIPK3) pathways were assessed by RT-qPCR in fetal tissues collected at 12 DPI. High viral load fetuses showed differential expression relative to the CTRL and UNINF ( $P<0.05$ for all). Brain tissue from HVL-VIA and HVL-MEC fetuses presented increased expression of CASP7, CASP8, RIPK3, HIF1a and IDO1. Fetal heart showed increased expression of CASP8, HIF1a, IDO and NOX1 and a decrease in NOS2 expression in infected groups. CASP7, CASP9, RIPK1 and RIPK3 were only increased in the heart of HVL-VIA while VEGFa was only increased for HVL-MEC fetuses. Thymus from HVL-MEC had decreased expression of CASP9 and there was increased IDO1 in all infected fetuses.

Conclusions: There is strong evidence of apoptosis occurring in the heart, liver and thymus of highly viral load fetuses at 21 DPI. Furthermore, there was clear upregulation of apoptotic genes in the heart of high viral load infected fetuses and less prominent upregulation in the brain of PRRSV-infected fetuses, whereas thymus appears to be spared at $12 \mathrm{DPI}$. There was no strong evidence of hypoxia at 12 DPI in brain and thymus but some indication of hypoxia occurring in fetal heart.
\end{abstract}

Keywords: Swine, Fetus, Apoptosis, Hypoxia, TUNEL, PRRS, Gene expression

\footnotetext{
* Correspondence: john.harding@usask.ca

'Western College of Veterinary Medicine, Saskatoon, 52 Campus Dr Saskatoon, Saskatchewan S7N 5B4, Canada

Full list of author information is available at the end of the article
}

(c) The Author(s). 2021 Open Access This article is licensed under a Creative Commons Attribution 4.0 International License, which permits use, sharing, adaptation, distribution and reproduction in any medium or format, as long as you give appropriate credit to the original author(s) and the source, provide a link to the Creative Commons licence, and indicate if changes were made. The images or other third party material in this article are included in the article's Creative Commons licence, unless indicated otherwise in a credit line to the material. If material is not included in the article's Creative Commons licence and your intended use is not permitted by statutory regulation or exceeds the permitted use, you will need to obtain permission directly from the copyright holder. To view a copy of this licence, visit http://creativecommons.org/licenses/by/4.0/ The Creative Commons Public Domain Dedication waiver (http://creativecommons.org/publicdomain/zero/1.0/) applies to the data made available in this article, unless otherwise stated in a credit line to the data. 


\section{Background}

Porcine reproductive and respiratory syndrome (PRRS) remains the most impactful viral pig disease in North America due to the heavy financial burden it has caused the pork industry [1]. Responsible for $45 \%$ of the economic losses, the reproductive form of the disease following PRRSV infection of sows during late gestation is characterized by abortions, fetal death, weak-born fetuses, and high pre-weaning mortality [2]. The mechanisms of fetal disease are not entirely understood and few studies have explored this topic, in part due to the lack of obvious fetal lesions [3, 4]. Following maternal infection, PRRSV rapidly infects the endometrium and crosses the epitheliochorial placenta to the fetus $[5,6]$.

We have previously reported that fetal serum is infected by 5 days after maternal inoculation (DPI) and fetal thymus by 8 DPI when fetal compromise first appeared [6]. Although gross and histopathologic lesions of infected fetuses have been characterized previously [3, 4, 7, 8], few studies have investigated possible mechanisms leading to fetal death after maternal PRRSV infection.

Due to the low frequency and inconsistency of fetal lesions, many studies have explored the maternal-fetal interface (MFI) for pathophysiological factors affecting fetal viability. Inflammatory lesions, placental detachment from endometrium, and apoptosis have been explored in both endometrium and placenta; however, none have proven directly responsible for fetal death [713]. Due to the infrequent but consistent finding of perivascular umbilical lesions in dead fetuses, hypoxia has also been proposed as a leading cause of fetal losses, due to the blood flow disruption $[7,14]$. This is supported by the observation that the odds of meconium-staining of fetal skin [8], an indication of fetal stress and early clinical sign of fetal compromise, is associated with the presence of umbilical cord and fetal lesions [8].

Apoptosis is a normal physiological process responsible for programmed cell death in a selective manner, which when deregulated can lead to pathology and death [15]. Frequently used to investigate apoptosis, the terminal deoxynucleotidyl transferase (TdT) dUTP nick end labeling (TUNEL) assay detects DNA fragmentation due to apoptosis. TUNEL has been previously applied in PRRSV studies to assess severity of apoptosis in infected tissues and to associate the severity of apoptosis to PRRSV viral load in placental tissue from infected pregnant gilts at 21 DPI [13]. In addition, this methodology has been used to demonstrate that PRRSV cell infection not only results in apoptosis of the infected cells, but also induces apoptosis of surrounding non-infected cells at 10 DPI [9].

Although the pathophysiologic events occurring in the endometrium and placenta following maternal infection may contribute to fetal compromise, fetal death may also involve events compartmentalized to the fetal side. The absence of fetal lesions in many compromised and dead fetuses [8] raises questions about events occurring at a cellular and subcellular level in fetal tissues. RNA-Seq has been utilized and shown that the fetal thymus responded to infection by mounting an innate immune response, followed by an inflammatory response [16]. In a targeted gene expression study [17], IFNB, IFNG, CCL2, CCL5, CXCL10 and IL10, were upregulated in fetal tissues of high viral load fetuses at 21 DPI, although only CCL5 was elevated in more than one tissue from high viral load meconium-stained fetuses compared to high viral load viable fetuses, indicating that fetal immune response is not the main cause of fetal death. Nonetheless, a suppression of the cell cycle coupled with an increase in cardiac stress were found in the hearts of high viral load fetuses at 21 DPI [18]. More recently, differential expression analysis of some 283 immune related genes using the NanoString platform on placental and thymic tissues from fetuses at different stages of infection demonstrated response in either tissues was only initiated following infection of the fetus per se [19].

With these indications that fetal demise might be influenced by events occurring not only on the maternal side, but also in the fetal compartment, we aimed to determine if there was evidence of apoptosis and hypoxia in fetal tissues and if it was more pronounced in compromised (meconium-stained) fetuses. We designed two studies, firstly to assess apoptosis in fetal tissues collected between PRRSV-infected and non-infected fetuses at 21 days post-infection (DPI); and secondly, to determine differences in gene expression related to apoptosis and hypoxia in PRRSV-infected and non-infected fetuses collected at 12 DPI. Both experiments used the best available tissues archived from PRRSV pregnant gilt challenge studies conducted at the University of Saskatchewan, Canada.

\section{Results}

Experiment 1: differences in apoptosis in fetal tissues at $21 \mathrm{DPI}$

In total, 100 fetuses were analyzed for apoptotic foci in LVR, THY and HRT. Only one fetus (HVL) had no TUNEL positive staining in THY, although its LVR had many TUNEL positive TUNEL foci. Only 8 fetuses had TUNEL positive staining in the HRT, all belonging to the HVL-MEC group. TUNEL staining foci were moderately to widely distributed in fetal THY and LVR and less abundant in the fetal HRT (Fig. 1). The limited TUNEL staining in the control group was within normal expectations (Additional file 1).

In the liver, TUNEL positive staining was distributed in all areas and found in hepatocyte nuclei (Fig. 1). The mean size of TUNEL positive foci (Fig. 2a) in the liver 


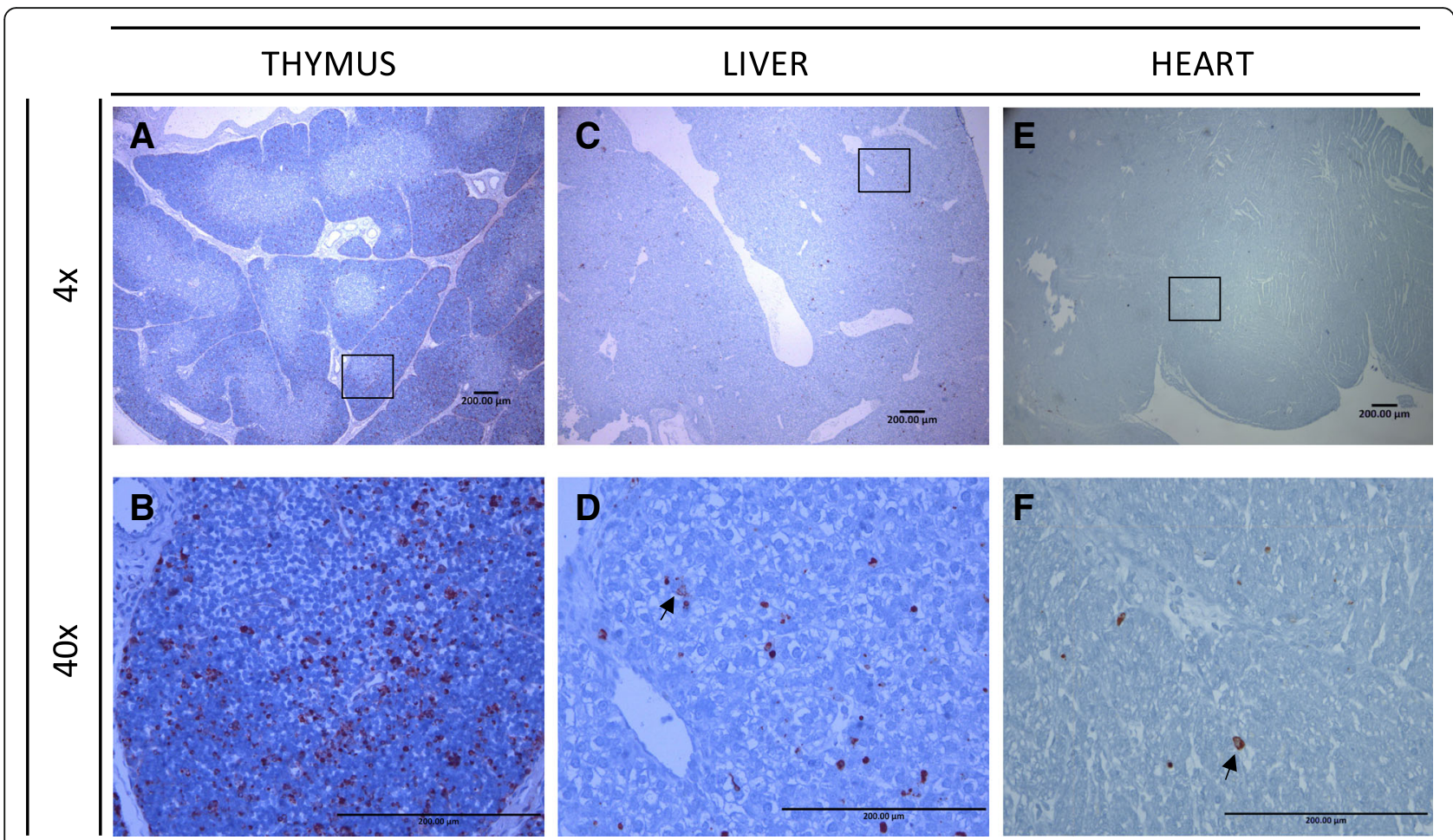

Fig. 1 TUNEL staining in three fetal tissues of PRRSV-infected fetuses. A Diffuse areas of apoptosis on fetal thymus; $\mathbf{B}$ Higher magnification fetal thymus to display apoptosis (arrow) in thymocytes; C Areas with multiple apoptosis staining on fetal liver; D Higher magnification fetal liver to display apoptosis (arrow) in hepatocytes; E Focal spots of apoptosis in the fetal heart (arrow); $\mathbf{F}$ Higher magnification fetal heart to display apoptosis (arrow) in myocytes

was significantly $(P=0.0009)$ larger in the HVL-VIA and HVL-MEC groups $\left(20 \pm 6.7 \mu \mathrm{m}^{2}\right.$ and $21 \pm 5 \mu \mathrm{m}^{2}$, respectively) compared to the CTRL and LVL groups (17 \pm $3 \mu \mathrm{m}^{2}$ and $16 \pm 4.2 \mu \mathrm{m}^{2}$, respectively). The number of TUNEL positive foci (Fig. 2b) was significantly $(P=$ $0.0004)$ greater in HVL-VIA and HVL-MEC fetuses (average $86.9 \pm 107.4$ and $68.3 \pm 32$, respectively) compared to the CTRL (average $48.9 \pm 36.8$ ) and LVL (average $46.5 \pm 66.1$ ) groups.

In thymus, TUNEL positive cells were diffusely distributed along the cortical and cortico-medullar regions, located in the thymocytes, mostly as single cell staining and rarely presenting in clusters. The number of stained foci differed among groups $(P=0.009)$ with the CTRL and LVL groups having similar counts; $66.2 \pm 29.6$ and $87.5 \pm 95.7$ positive stained foci on average, compared to $131.4 \pm 118.7$ and $192.5 \pm 202.3$ positive stained foci for the HVL-VIA and HVL-MEC groups, respectively. Furthermore, the mean size of TUNEL positive foci in thymus was significantly $(P=$ $0.0002)$ larger in the highly infected animals (HVL-VIA $=$ $16.8 \pm 5.9 \mu \mathrm{m}^{2}$ and HVL-MEC $\left.=16.3 \pm 5.1 \mu \mathrm{m}^{2}\right)$ compared to the CTRL and LVL-VIA animals $\left(13.5 \pm 2.1 \mu^{2}\right.$ and $13.3 \pm 3.6 \mu \mathrm{m}^{2}$, respectively).

Only eight of the 100 fetal hearts, all from HVL-MEC fetuses, had any positive TUNEL staining and in these fetuses the staining was located in the cardiomyocytes.
The mean number of TUNEL positive foci were $301.5 \pm$ 373.9 in HVL-MEC fetuses. The average size of positive stained foci was $17.6 \pm 7.6 \mu \mathrm{m}^{2}$ for HVL-MEC fetuses.

The TUNEL staining foci size on thymus tissues was significantly correlated $(P<0.05)$ to vasculitis distribution and severity in MFI, as well as endometrial inflammation, previously analysed for these animals [13]. Similarly, the foci counts on fetal liver were also correlated to vasculitis severity in MFI. Although the correlations were not strong (Table 1), it indicates a progression in or aggravation of in fetal disease concomitant with progression of lesion severity on the MFI.

\section{Experiment 2: apoptosis and hypoxia gene expression in fetal tissues at $12 \mathrm{dpi}$}

A number of genes were significantly upregulated following fetal infection $(P<0.05)$. The expression of IDO1 was significantly increased in the BRN of HVL-VIA and HVL-MEC fetuses, consistent with PRRSV infection (Fig. 3). HIF-1 $\alpha$ was also significantly elevated in BRN of both PRRSV-infected groups, possibly indicating the activation of hypoxia mechanisms. Additionally, significant upregulation of CASP7, CASP8 and RIPK3 genes of HVL-VIA and HVL-MEC groups indicate the activation of the apoptosis pathway in fetal BRN. The expression of no other genes differed significantly from CTRL. 


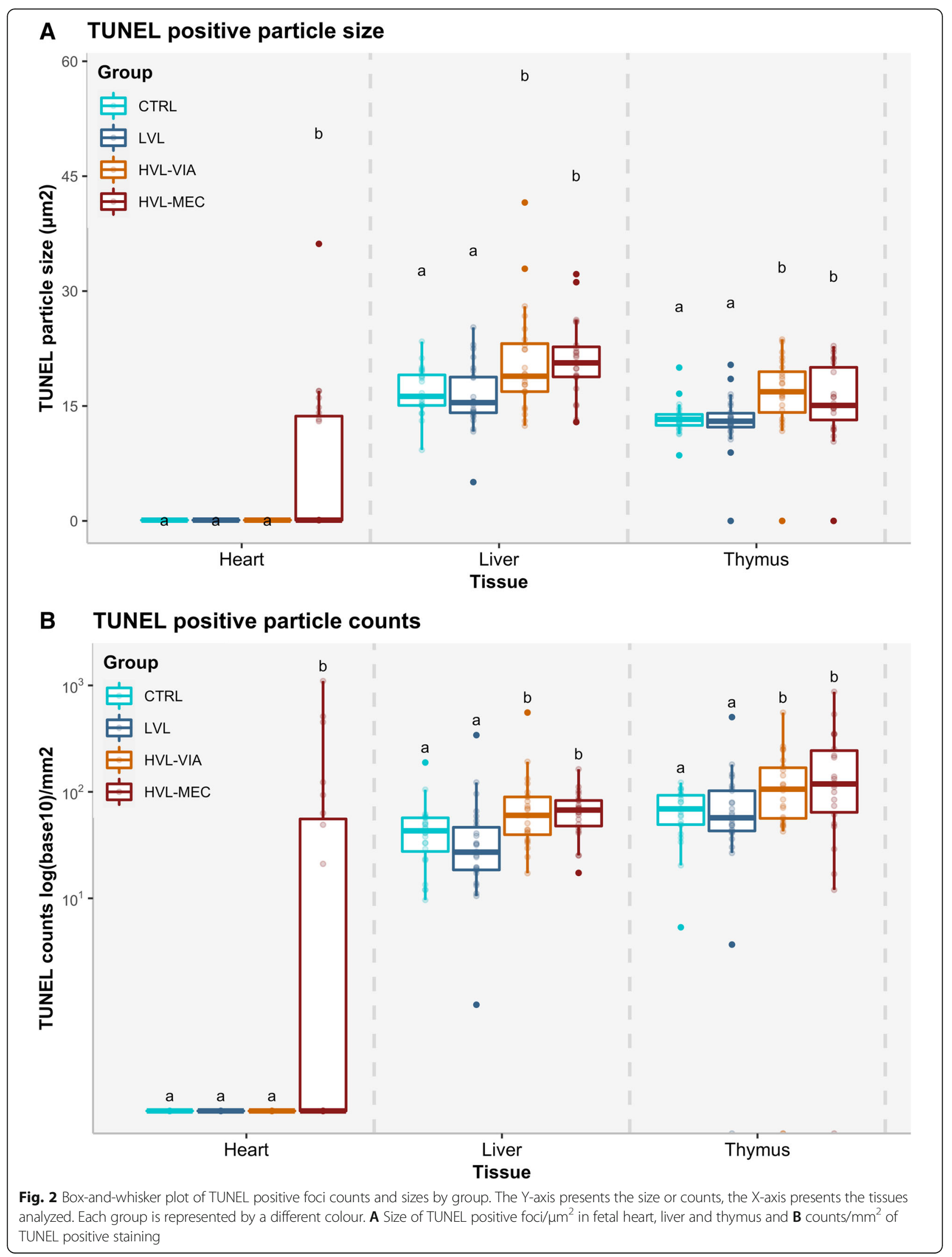


Table 1 Spearman's rank correlation test results between liver or thymus (TUNEL foci counts or sizes) and maternal-fetal interface (MFI) lesion severity ${ }^{a}$

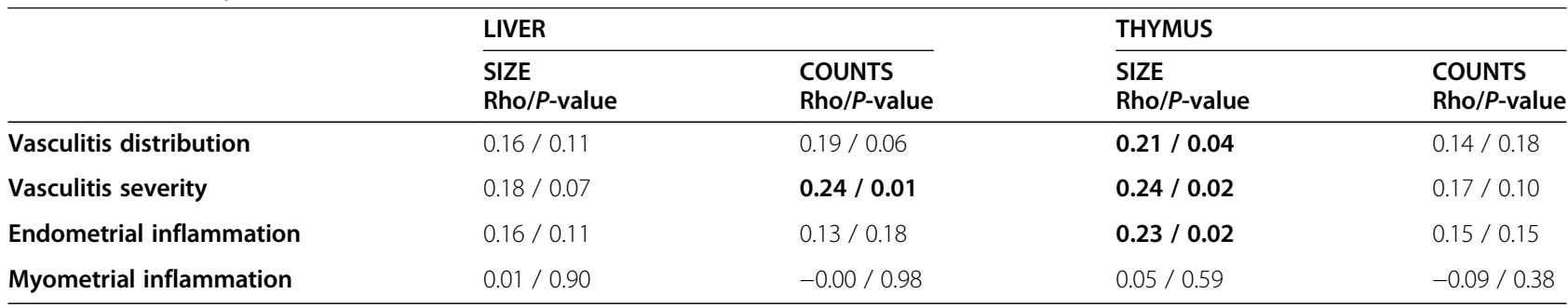

${ }^{\mathrm{a}} \mathrm{MFI}$ lesion scores as previously evaluated [13]

Of the three tissues examined, fetal heart was the most affected (Fig. 4). The expression of all tested genes except for CASP3 and LDHA were significantly $(P<0.05)$ altered compared to CTRL. The marked upregulation of IDO1 (almost $10^{2}$ fold change) in HVL-VIA and HVLMEC fetuses is indicative of the infection of the HRT. The HVL-VIA group had the most significant upregulation of genes related to apoptosis (CASP7, CASP8, RIPK1, and RIPK3), whereas only CASP8 was significantly upregulated in HVL-MEC compared to both noninfected groups. CASP9 gene expression did not differ among HVL-VIA versus CTRL and UNINF groups but was significantly upregulated compared to HVL-MEC. With the exception of CASP8, HVL-MEC did not differ significantly from CTRL and also did not differ significantly from HVL-VIA in the expression of CASP7,
CASP8 and RIPK1. The UNINF group had expression patterns similar to the CTRL group in most of the targeted genes but presented significant downregulation of CASP7. With regards to the hypoxia related genes, HIF-1 $\alpha$ was significantly upregulated in both HVLVIA and HVL-MEC, while the UNINF group was intermediary between CTRL and the infected groups. The HVL-VIA group showed marked upregulated expression of NOX1, while HVL-MEC were intermediary between HVL-VIA and both non-infected groups. The only downregulated gene in the infected animals was NOS2, where HVL-MEC was significantly different from the CTRL group and HVL-VIA was intermediary between CTRL and HVL-MEC. The UNINF group was similar to the CTRL group in all genes related to hypoxia.

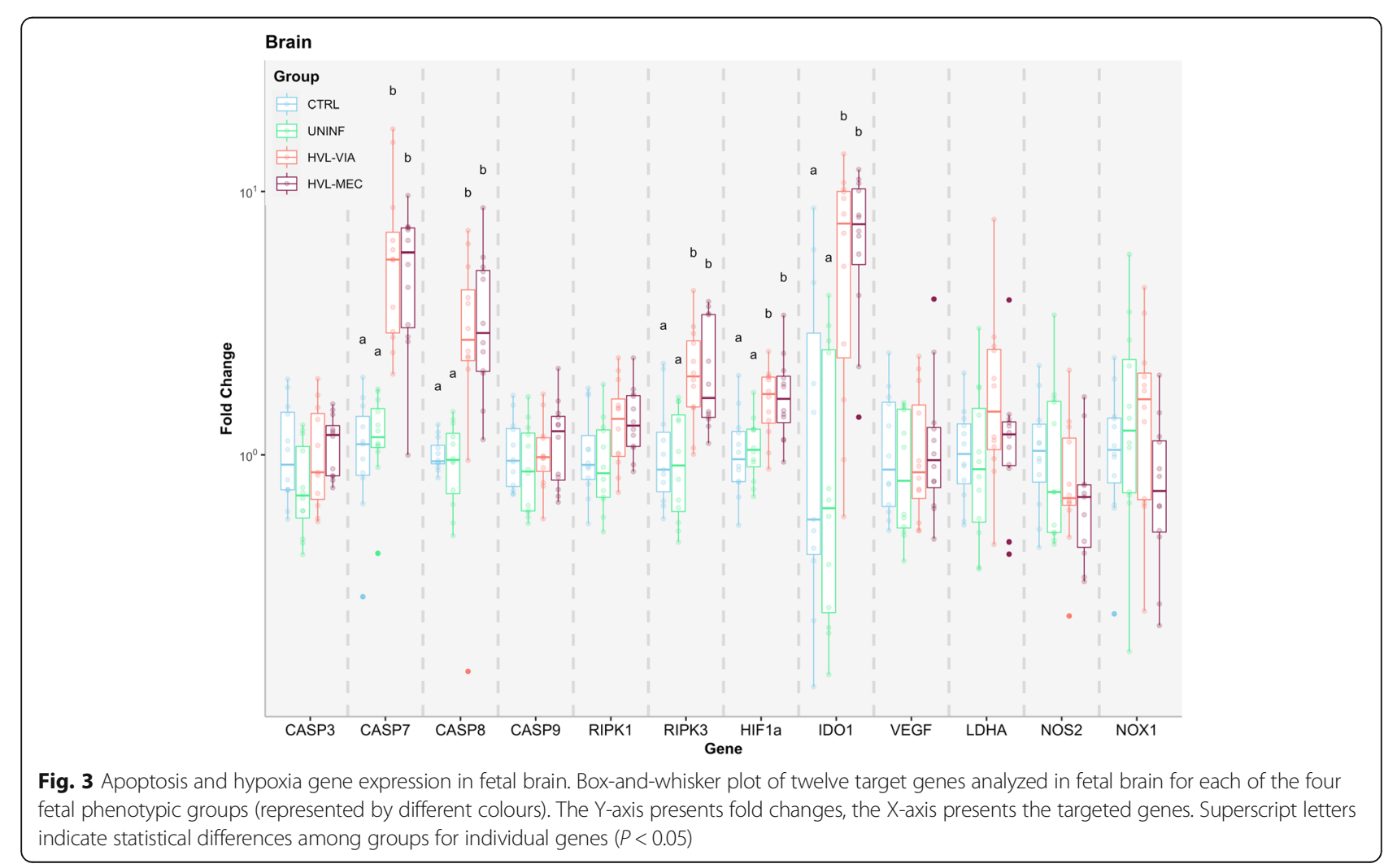




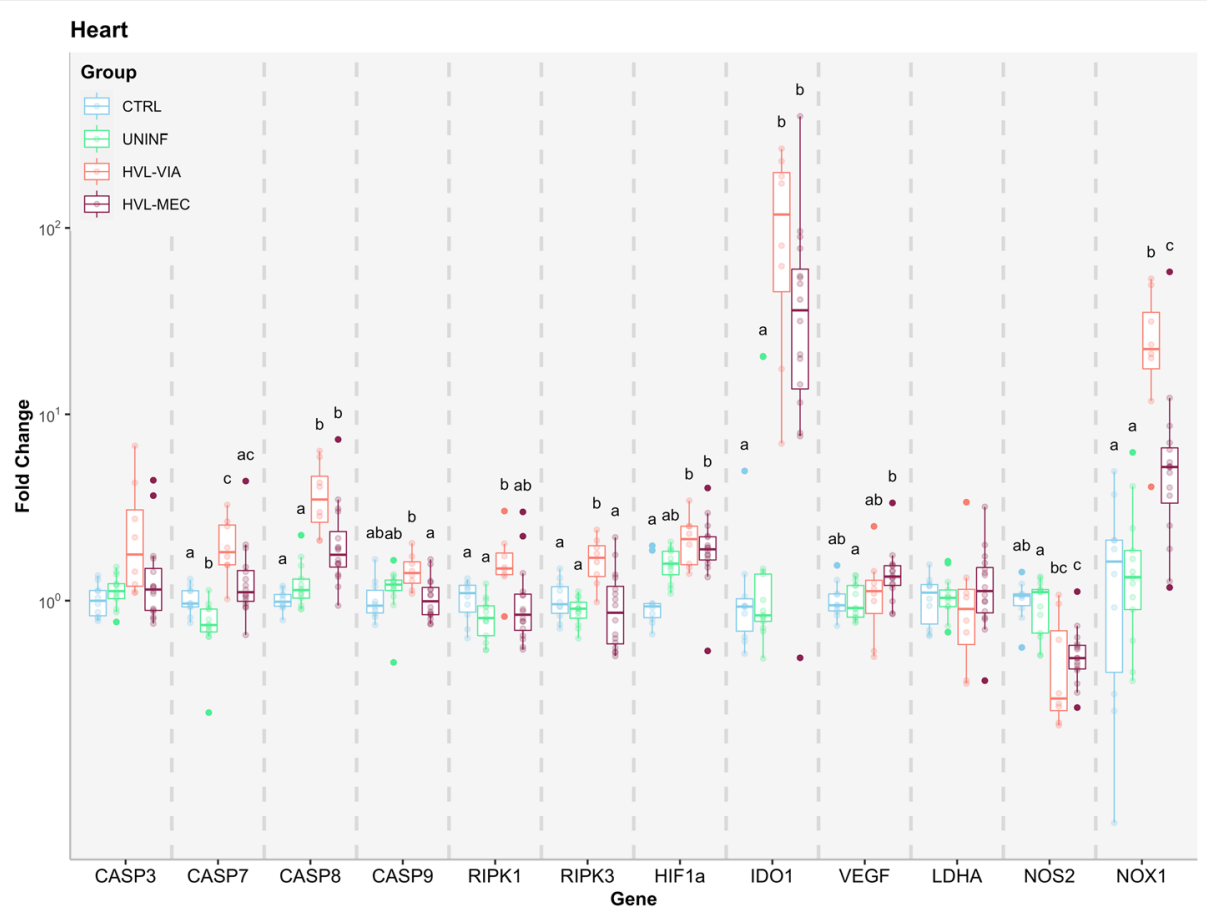

Fig. 4 Apoptosis and hypoxia gene expression in fetal heart. Box-and-whisker plot of twelve target genes analyzed in fetal heart for each of the four fetal phenotypic groups (represented by different colours). The $\mathrm{Y}$-axis presents the fold change, the $\mathrm{X}$-axis presents the targeted genes. Superscript letters indicate statistical differences among groups for individual genes $(P<0.05)$

Fetal thymus was the least affected tissue in this study (Fig. 5). The HVL-VIA group had a significant upregulation of IDO1, consistent with PRRSV-infection. Expression of IDO1 was numerically increased in HVL-MEC except for one fetus in this group. There is no explanation for this outlier fetus (G189-R3), as the fetus was phenotypically representative of the group. Three UNINF and one CTRL fetus also had upregulated IDO1 expression despite being uninfected. The only other altered gene among groups was CASP9, which was significantly downregulated in HVL-MEC compared to the HVL-VIA, but neither of these groups differed from the CTRL and UNINF groups. No correlation was found between target genes fold change and vasculitis in endometrium or placenta, endometritis, placentitis, and placental detachment (unpublished data).

A heatmap summarizing the gene expression findings is presented in Fig. 6.

\section{Discussion}

Although first described over 30 years ago in North America, Europe and Asia (as reviewed by Christianson [20]), porcine reproductive and respiratory syndrome (PRRS) is still one of the most damaging diseases affecting the pork industry. The reproductive form of the disease is responsible for $45 \%$ of all economic losses caused by PRRS virus infection [1]. The infection of pregnant gilts and sows in their last third of gestation often results in only mild clinical signs in the dam, however, the litter can be severely affected by abortions, fetal death, weak born piglets and pre-weaning mortality [21]. The mechanisms of maternal uterine infection and transplacental transmission have been explored [8-10, 13, 22, 23] and a few hypothesis about transplacental infection have been proposed and are reviewed in detail elsewhere [24]. In spite of the rapid development of severe endometritis, placentitis, and endometrial vasculitis subsequent to PRRSV infection, it is uncertain if those lesions result in fetal death, since fetuses present with minimal and nonlethal lesions when found dead [4, 14]. However, previous studies have concluded that there is no relationship between MFI lesions or viral load and fetal death [7, 12]. Thus, our goal was to investigate the fetal mechanisms that are potentially leading to compromise and death following PRRSV infection of third trimester fetuses.

Two separate animal experiments were conducted aiming to find possible insights into fetal death mechanisms following PRRSV infection. Our first experiment investigated apoptosis in fetal tissues after 21 days of maternal inoculation, using paraffin embedded samples from a previously described project [25] conducted in 2012. This was a follow up to our previous investigation in which apoptosis in the MFI (determined by TUNEL staining) was positively associated with PRRSV concentration in the fetal thymus and to meconium-staining of the fetus [13]. The results from this first experiment guided our second 


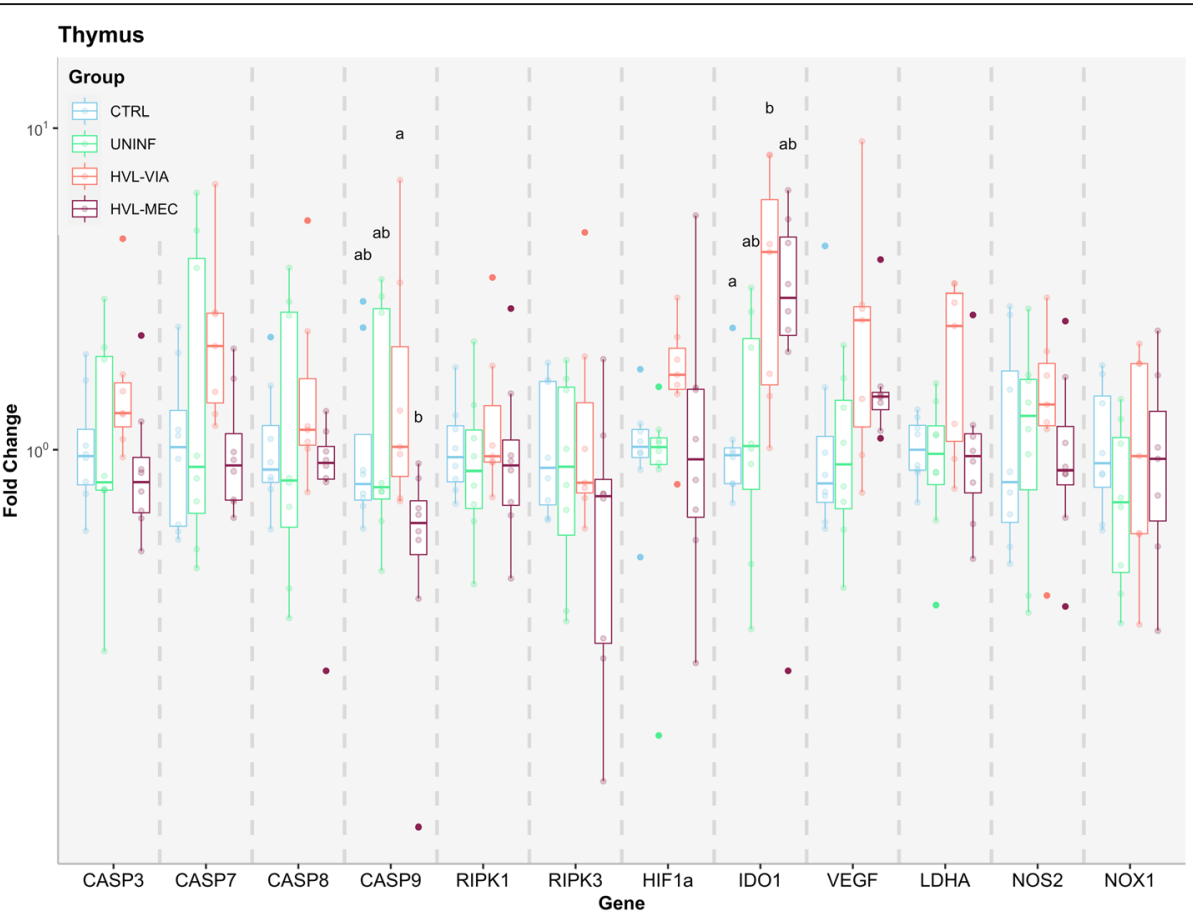

Fig. 5 Apoptosis and hypoxia gene expression in fetal thymus. Box-and-whisker plot of twelve target genes analyzed in fetal thymus for each of the four fetal phenotypic groups (represented by different colours). The $Y$-axis presents the fold change, the $X$-axis presents the targeted genes. Superscript letters indicate statistical differences among groups for individual genes $(P<0.05)$

experiment that was designed to investigate an earlier stage of apoptosis at 12 days post-infection (12 DPI) through gene expression. The snap frozen tissues for this experiment were collected from a 2017 animal experiment. We also investigated the role of hypoxia as previous research suggested its involvement in fetal compromise [7,
14]. Unfortunately, not all "Experiment 2" fetal samples collected yielded high quality mRNA, explaining the difference in tissue samples used between experiments.

The four fetal phenotypic groups selected for these experiments are representative of the evolution of PRRSV fetal infection and disease. The UNINF and LVL-VIA

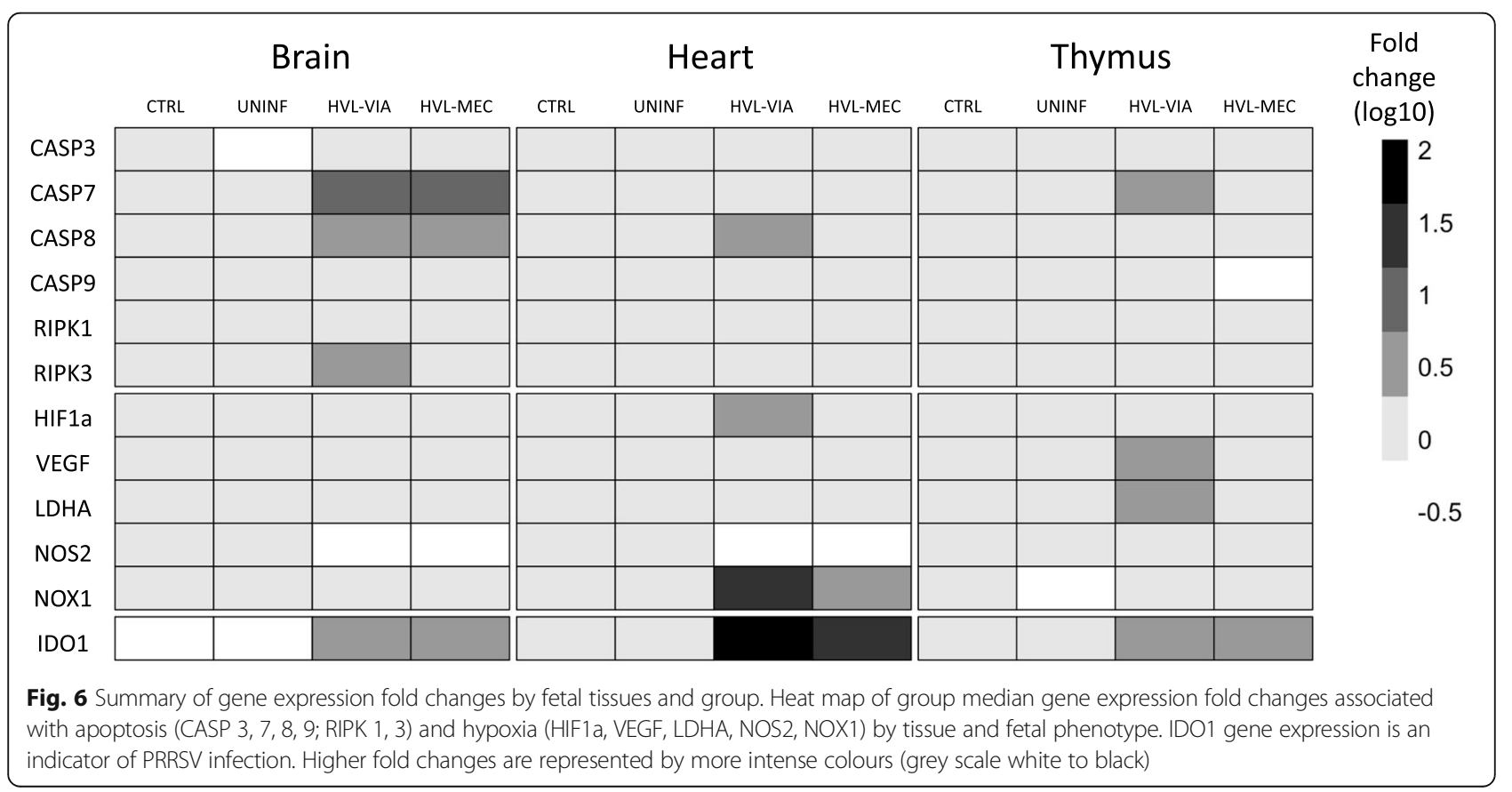


groups contained either non-infected or very low viral load fetuses from inoculated/infected dams. These are considered the most resistant fetuses [18], escaping infection entirely or sustaining a low rate of viral replication resulting in low levels of virus detectable in SER, THY, and PLC. UNINF fetuses are rather rare, although they would be of high value to the pork industry. Our use of the four fetal phenotypic groups also enabled investigation of the mechanisms that may contribute to fetal death and whether those mechanisms are initiative by maternal or fetal infection; i.e., if they are initiated only after the fetuses per se becomes infected or if there is a threshold of viral concentration to be achieved before disease starts.

Although it is unknow if UNINF fetuses would have been alive and healthy if gestation was taken to term (gestation day 115), they were more resistant than the HVLVIA and HVL-MEC fetuses at the termination of the experiment (gestation day 106). By contrast, the HVL-VIA fetuses were the most tolerant or resilient fetuses [18] because in spite of high viral load, they remain viable. The HVL-MEC group was the most susceptible [18]. Fetal meconium-staining is largely recognized as a sign of multi-factorial in-utero distress that leads the fetus to defecate or regurgitate into the amniotic sac resulting in contamination of the skin (and sometimes lung) by this yellowish fecal matter. A positive relationship between high PRRSV viral load and meconium-staining of the fetus has been previously reported, indicating this is an initial step towards fetal compromise and death after infection [25]. The most susceptible fetuses are those that die following maternal PRRSV infection. Although decomposed and autolyzed fetuses were present in our challenge trials, we did not collect tissue samples from these fetuses because the mRNA quality was subpar.

In our first experiment, TUNEL staining in liver and thymus confirmed the association between DNA fragmentation and HVL-VIA and HVL-MEC fetuses that was previously observed [13], where the number of TUNEL positive foci in the MFI were related to the HVL-VIA and HVL-MEC phenotypes at 21 DPI. The same relationship was found in fetal heart samples with HVL-MEC fetuses having greater counts of TUNEL positive foci than the CTRL, LVL-VIA and HVL-VIA groups. This result also agrees with a recent study investigating disruption of the fetal thyroid hormones in PRRSV-infected fetuses [18], where the HVL-MEC group was more affected than the respective CTRL, UNINF, and HVL-VIA groups. The diffuse distribution of the apoptotic foci in the liver and thymus may indicate the apoptotic process is advanced in those tissues, possibly contributing to fetal demise.

By evaluating the size of TUNEL positive foci we aimed to determine any association with the progression of the disease and/or viral load of fetuses. Although no standards to characterize these findings by size exist to our knowledge, we hypothesize that it can, at least, indicate the abundance and extent of the apoptotic process in the affected tissues. Statistically, there were differences among the groups, where the highly infected animals (HVL-VIA and HVL-MEC in LVR and THY, HVLMEC in HRT) presented with larger foci than the noninfected groups (UNINF, CTRL). We interpret these results as confirmation that the highly infected animals are in a more severe state of apoptosis, which may contribute to fetal demise or death.

Based on insights from the first experiment using 21 DPI tissues, we investigated an earlier timepoint (12 DPI) to assess gene expression of apoptosis initiators and executioners. Apoptosis is the programmed cell death, regulated by a family of cysteine proteases (caspases; CASP) [15] along two main pathways: intrinsic and extrinsic. The intrinsic pathway is very well-regulated and initiated by mitochondrial perturbation resulting from cellular stress or cytotoxic insults. It is mainly regulated by CASP-9, an initiator caspase, that subsequently activates the effector, CASP-3 [15]. PRRSV activates the extrinsic apoptotic pathway after infecting the MFI $[9,13]$, which can be initiated via the TNF receptor (TNFR) family coupled to extrinsic signals. The extrinsic pathway is mainly regulated by the initiator, CASP-8, which subsequently activates CASP-3 and CASP-7 [15].

The TNFR and other inflammatory signals can also initiate the necroptosis pathway. Necroptosis is another form of programmed cell death that shares common reactions and processes with both apoptosis and necrosis. Also classified as a "programmed cell necrosis", it is mainly regulated by the receptor-interacting protein kinases 1 and 3 (RIPK1 and RIPK3) [26]. Although there are many cells and signals involved in the extrinsic apoptotic pathway and the necroptosis pathway, we focused our investigation on expression of the main genes involved in both (to which we will refer here simply as "apoptosis") in fetal tissues after maternal PRRSV inoculation.

There was a remarkable difference in gene expression across tissues and phenotypic groups. Apoptosis related genes were typically over expressed in brain and heart of PRRSV-infected fetuses, confirming that infection induces cell death in fetal tissues. Importantly, this apoptotic fetal response is dependent on infection of the fetus, not by maternal infection as noted by the lack of statistical difference between the UNINF and CTRL groups. It is also in general agreement with previous findings, where increased counts of apoptotic cells in the MFI were associated with increased fetal thymus PRRSV viral load [13].

One of the most unexpected and potentially important findings is that heart was the most affected organ, 
presenting with the higher number of altered genes and higher fold change averages among the three analyzed tissues. This aligns with the findings of Pasternak [18], where after fetal PRRSV infection genes related to cell cycle progression were downregulated and genes related to cell cycle inhibition were upregulated in the fetal heart. Moreover, this result partially agrees with our TUNEL findings, where evidence of apoptosis was only found in the hearts of HVL-MEC group, whereas gene expression was more consistently altered in HVL-VIA fetuses. Additionally, early experiments demonstrated the presence, albeit inconsistent, of virus in the heart of PRRSV challenged fetuses using culture recovery methods [27]. This finding is consistent with immune histochemical analysis of the postnatal heart of piglets following in utero infection $[28,29]$. The degree of apoptosis and gene expression changes in fetal heart following local infection may therefore be a key indicator of fetal outcome. Interestingly, fetal thymus, the putative primary site of PRRSV replication on the fetus [27], despite presenting with greater counts and larger sizes of TUNEL positive foci in infected fetuses at 21 DPI, was surprisingly the least altered tissue, having only two out of 12 genes differentially expressed among groups of fetuses. This finding may be due to the early timepoint of sample collection, or to the fact that, as the main viral replication site, the immunosuppressing characteristics of the virus [30] are more influential in thymus than other tissues. Although thymus is considered a tissue of great importance in fetal PRRSV infection, it is not a vital organ for fetal survival in the acute stages of the disease and may therefore only be relevant in the experimental context as a measure of fetal infection.

Hypoxia, the deprivation of adequate levels of oxygen in a tissue, has been theorized as a potential cause of PRRSV-related fetal death based on the observation of umbilical cord lesions [14], which were found to be associated with meconium-staining of the fetus [8]. As some umbilical cord lesions have been observed in dead fetuses from PRRSV infected dams, it is plausible that a reduced blood flow would lead to decreased levels of available oxygen for the fetus. Inflammatory lesions within the MFI and placental detachment may also lead to reduced maternal oxygen transfer to the progeny. These theories prompted our interest in testing the main genes related to hypoxia and its consequences. HIF- $1 \alpha$, a member of the hypoxia-inducible factors (HIFs), is a master regulator of the adaptive response to low levels of oxygen [31]. It is ubiquitously expressed and under normal conditions (normoxia), its subunits are hydroxylated by prolyl hydroxylases (PHD1-3) and go under proteasomal degradation by the von Hippel Lindau (VHL) E3 ubiquitin ligase complex [31]. However, during hypoxia the PHD enzymes are unable to function, suppressing HIF- $1 \alpha$ hydroxylation and stabilizing its subunits. From there, HIF- $1 \alpha$ can dimerize with HIF-1 $\beta$ and promote transcription of other hypoxia-responsive target genes such as vascular endothelial growth factor (VEGF $\alpha$ ), lactate dehydrogenase A (LDHA), nitric oxide synthase 2 (NOS2), and NADPH oxidase 1 (NOX1) [31, 32]. In fetal brain, expression of HIF-1 $\alpha$ was upregulated in highly infected fetuses (HVL-VIA and HVL-MEC) compared to CTRL and UNINF, however, none of the other hypoxia-responsive genes were altered. This might indicate an early response to hypoxia or no response at all. HIF- $1 \alpha$ can be also involved in the cell death cycle by activating expression of genes in the apoptosis pathway [33], which may explain its upregulation. By contrast, the heart of highly infected fetuses presented with multiple altered genes in addition to HIF-1 $\alpha$. The VEGF $\alpha$ gene was slightly increased in HVL-VIA (1.07 fold changes) and HVL-MEC (1.25 fold changes) groups, suggesting an increase in the proliferation and migration of vascular endothelial cells to provide a larger vascular network for oxygen exchange in response to hypoxia. Much greater differences in expression were observed in the NOX1 (NADPH oxidase 1) gene in the heart of infected animals. NOX1 is involved in many physiological pathways, but it is normally responsible for catalyzing the production of reactive oxygen species (ROS) involved in vascular system. ROS are produced in very low amounts under normal situations, however, ROS can be induced by an increase of NOX1 resulting in damage to cellular proteins, RNA, DNA and lipids. More importantly in this scenario, it impairs the PHD enzymes, decreasing the hydroxylation of HIF-1 $\alpha$ [34]. In any case the degree of disruption within this pathway is consistent with previous work by Pasternak et al. [18] showing the high degree of susceptibility of this critical organ to PRRSV infection.

The downregulation of inducible nitric oxide synthase gene (iNOS or NOS2) in the HVL-MEC fetuses (and a trend for the HVL-VIA group) was interesting and unexpected. The production of this enzyme can be induced by inflammatory cytokines such as TNF- $\alpha$ and INF-gamma that are present in sera of PRRSV infected fetuses at or over 19 DPI [17, 27]. NOS2 induces dilatation of blood vessels in response to hypoxia in order to increase blood (and oxygen) availability [35]. The unexpected result might indicate the levels of TNF- $\alpha$ and INF-gamma might not be sufficiently increased at the termination point (12 DPI) used in this project to cause the expected effects. As none of the hypoxia related genes were altered in THY, it is possible that this tissue is not experiencing any hypoxia. However, it's important to note that in mice the thymus was observed to be a naturally hypoxic tissue when compared to other organs and blood cells, enabling the thymus to be better adapted to hypoxia [36]. This may 
explain why the expected responses was not initiated. Moreover, as $\mathrm{T}$ cells have a lower activation in hypoxic environments [37], this might be a factor that makes thymus a preferred tissue for PRRSV replication.

The only gene that presented a constant pattern throughout all the tissues was indoleamine 2, 3-dioxygenase 1 (IDO1), where its expression was consistently upregulated in highly infected fetuses. This enzyme facilitates tryptophan metabolism and the production of kynurenine [38], which interestingly, was increased in HVL-VIA fetuses compared with UNINF fetuses [39]. Kynurenine is involved in the "metabolic immune regulation" mechanism and its gene expression can be regulated by TNF- $\alpha$ and INF-gamma, as reviewed by Richardson [38]. Because expression in the UNINF and CTRL groups were similar, we deduce that this response to infection is only elicited when the virus infects the fetus (not only the dam), confirming a fetal compartmentalized response to PRRSV infection.

\section{Conclusions}

The findings of this study bring new insights into fetal demise mechanisms after maternal inoculation with PRRSV. Apoptosis is clearly a compromising mechanism evident in multiple organs in the highly infected fetuses. It is plausible the observed apoptotic tendencies, particularly within the heart, contribute to fetal compromise and death beginning as early as 12 DPI and still evident at 21 DPI. Both HVL groups (-VIA and -MEC) displayed indications of an apoptotic process in the brain, while fetal heart is the most severely affected fetal organ following PRRSV infection, showing signs of hypoxia in addition to the apoptosis process.

\section{Material and methods \\ Experiment 1: apoptosis in fetal tissue at $21 \mathrm{DPI}$ Animals}

Animal work was conducted in strict accordance with the guidelines of the Canadian Council of Animal Care and with approval of the University of Saskatchewan's Animal Research Ethics Board (Protocol \#20110102). This project has been described in detail elsewhere [25] and complied to the ARRIVE Guidelines (https:// arriveguidelines.org/arrive-guidelines) where feasible. In short, 133 purebred Landrace gilts bred to York boars were transported, in bi-weekly repetitions, to a biocontainment level 2 (BCL2) animal facility at University of Saskatchewan at day 80 of gestation. After 5 days of acclimation, 114 randomly selected gilts were inoculated with $1 \times 10^{5}$ TCID $_{50}$ PRRSV NVSL 97-7895; 2 mL intramuscular (IM) and $1 \mathrm{~mL}$ into each nostril. Nineteen gilts were mock inoculated with minimal essential medium to serve as control animals.

\section{Sample collection}

At 21 DPI, gilts were humanly euthanized by intravenous barbiturate overdose followed by cranial captive bolt and exsanguination. The uterus was removed, placed linearly and opened enabling fetal assessment. Fetuses were identified and numbered in accordance with their position in the right or left uterine horn. Their preservation status was determined as: viable (VIA live, normal skin color), meconium-stained (MEC; live, normal skin covered with meconium), decomposed (DEC; dead, pale skin, sometimes edematous), autolyzed (AUT; dead, pale or dark skin, friable or liquefied organs) or mummified (MUM; dehydrated, dark brown color, crown-rump length $<20 \mathrm{~cm}$ ). Samples were not collected from AUT and MUM fetuses. From all other fetuses, liver (LVR), heart apex (HRT), and thymus (THY) were collected into $10 \%$ buffered formalin for routine histopathologic processing. Serum (SER) and THY were collected and frozen at $-80^{\circ} \mathrm{C}$ for PRRSV RNA quantification.

\section{PRRS virus quantification and group selection}

PRRSV was quantified in fetal THY and SER by RTqPCR as previously described [25]. Briefly, RNA was extracted from $140 \mu \mathrm{L}$ SER using the QIAamp Viral RNA mini kit (Qiagen Inc., Toronto, ON) or from 10 to 20 mg THY using the RNeasy extraction kit (Qiagen Inc.) according to the manufacturer's instructions. Primers targeting the C-terminal end of ORF7 of NVSL 97-7895 were designed and a HindIII linearized plasmid, pCR2.1TOPO-NVSL, containing a $446 \mathrm{bp}$ sequence of ORF7 serial dilution was used as a standard curve. The Master mix (Brilliant II RT-qPCR Low ROX 1-Step Master Mix, Agilent technologies Canada Inc., Mississauga, $\mathrm{ON}$ ) was used and the reactions were run on a Stratagene MX3500P (Agilent Technologies, Mississauga, ON). Results were transformed to log (base 10).

PRRSV-infected viable fetuses were further divided into a low viral load viable group (LVL-VIA, $n=25$ ) with viral load (VL) lower than $4.1 \log _{10}$ copies $/ \mu \mathrm{L}$ or $\mathrm{mg}$ in both SER and THY $(19 / 25$ or $76 \%$ had less than $1 \log )$, and a high VL viable group (HVL-VIA, $n=25$ ) group with viral load $(\mathrm{VL})$ higher than $5.0 \log _{10}$ copies $/ \mu \mathrm{L}$ or mg. In addition, a HVL-MEC group $(n=25)$ was selected to represent the most PRRSV-susceptible set of fetuses. Viral load by group is graphically displayed in Additional file 2. In addition to meeting viral load criteria, nearly all fetuses had been included in a previous study [13] investigating apoptosis at the maternal fetal interface using the TUNEL assay. As much as possible, infected fetuses from multiple phenotypic groups were nested within litter. In fulfilment of these criteria, the 75 LVL-VIA, HVL-VIA and HVL-MEC fetuses originated from 48 PRRSV-challenged gilts (23 providing more than 1 fetal group). Control (CTRL) fetuses $(n=25)$ were 
derived from 6 non-challenged gilts (4-5 per gilt) and all were included in the previous apoptosis study of MFI tissues [13].

\section{TUNEL assay of fetal tissues}

As previously described [13], formalin-fixed paraffin embedded fetal organ samples were deparaffinized and rehydrated, followed by protein digestion using Proteinase $\mathrm{K}$ solution (15 min). Hydrogen peroxide (3\%) was applied ( $5 \mathrm{~min}$ ) to block endogenous peroxidase activity, followed immediately by application of the equilibration buffer provided with the ApopTag Plus Peroxidase In Situ Apoptosis Detection Kit (Millipore Canada Ltd., Etobicoke, Ontario) for $10 \mathrm{~s}$ at room temperature. Terminal deoxynucleotidyl transferase (TdT) enzyme was then applied at $37^{\circ} \mathrm{C}$ for $1 \mathrm{~h}$ in a humidity chamber. Slides were rinsed and the signal was revealed using 3Amino-9-Ethylcarbazole (AEC) chromogen for $15 \mathrm{~min}$. The whole slides were scanned at 20X magnification using OlyVIA (Olympus Corp., Tokyo, Japan), and converted to JPEG format. Image conversion was conducted using ImageJ (version 1.50i) and the quantitative analysis of TUNEL positive staining was completed using ImagePro Premier software (Media Cybernetics, Inc., Rockville, MD, USA) using the parent-child application for ten random microscopic fields for heart, brain and thymus.

\section{Statistical analysis}

The raw count data was exported to Microsoft Excel and Stata (StataCorp, College Station, TX) to categorize TUNEL positive staining counts by foci size and to calculate the average foci size per $\mu \mathrm{m}^{2}$ of tissue for each size category. Three size categories were established: "large foci" above $23 \mu \mathrm{m}^{2}$; "medium foci" between 5 and $23 \mu \mathrm{m}^{2}$; and "small foci" below $5 \mu \mathrm{m}^{2}$. The "small foci" category was removed from further analyses because they were considered artifacts, or not related to cell-associated PRRSV infection, as PRRSV infection is restricted to porcine alveolar macrophages or differentiated blood monocytes [40], which measure between 15 and $20 \mu \mathrm{m}$ [5]. Data was tested for normality using the Shapiro-Wilk test. Differences among the fetal groups in the number of positive TUNEL positive foci counts for each tissue were examined using Kruskal-Wallis and post hoc Dunn's tests and a Benjamini-Hochberg multiple comparison adjustment. The strength of relationship between fold changes of each target gene and MFI lesions was assessed using Spearman's rank correlation test, with significance $P<0.05$, and correlation as: none $($ rho $=0)$, weak $(0.1<\mid$ rho $\mid<0.3)$, moderate $(0.3<\mid$ rho $\mid<0.6)$, strong $(0.6<\mid$ rho $\mid<0.9)$, and perfect $(\mid$ rho $\mid>0.9)$ for both positive and negative correlations [41]. The pathologic evaluation and scoring of the MFI samples was previously published by Novakovic [13].
Experiment 2: apoptosis and hypoxia gene expression in fetal tissues at $12 \mathrm{dpi}$

\section{Animals}

Animal work was conducted in strict accordance with the guidelines of the Canadian Council of Animal Care and with approval of the University of Saskatchewan's Animal Research Ethics Board (Protocol \#20160023). This project has been described elsewhere [18]. Briefly, 36 purebred Landrace gilts bred to York boars were purchased at 80 days of gestation from the same high health, PRRSV-free farm as used in Experiment 1. For each of 6 weeks, six gilts were transferred to a BCL2 animal facility at the University of Saskatchewan. After 5 days of acclimation, five gilts blocked by sire were inoculated (INOC) as previously described for "Experiment 1". One gilt housed in a separate room was similarly mock inoculated with minimum essential medium (CTRL). In total, 30 gilts were INOC and six gilts served as CTRL.

\section{Sample collection}

After 12 DPI, gilts were euthanized and necropsied as described for Experiment 1, as was fetal preservation classification and sample collection. In addition, placenta (PLC) was manually separated from the endometrium (END) and along with fetal brain (BRN) were snap frozen in liquid nitrogen.

\section{PRRS virus quantification and group selection}

Virus concentration was measured in PLC, SER and THY for each fetus, as previously described [6] and followed the same viral extraction procedures as Experiment 1. Thereafter, a one-step reverse transcriptase qPCR kit (iTaq Universal Probes 1-Step Kit, BioRad, Mississauga, Canada) was employed for the absolute quantification of viral RNA, using the same primers [25], standard curve, and quality control samples as in Experiment 1. Based on the quantification results, the fetuses were further classified as uninfected (UNINF) representing the fetuses from inoculated gilts that had no detectable infection, and as high viral load (HVL) with viral load over $4.5 \log _{10}$ target RNA copies per mg or $\mu \mathrm{L}$ in PLC, SER, and THY.

Tissues including brain (BRN, $n=12$ /group, total $=48$ ), HRT $(n=8-16 /$ group, total $=47)$ and THY $(n=7-8 /$ group, total $=31$ ) were selected from fetuses of four phenotypic groups based on the preservation status of the fetus and its viral load in PLC, SER, and THY: control fetuses from non-inoculated gilts (CTRL, $n=30$ ); viable fetuses from inoculated gilts that escaped infection (UNINF, $n=33$ ); viable high viral load fetuses (HVL-VIA, $n=24$ ); and high viral load meconium-stained fetuses (HVL-MEC, $n=36$ ) (Additional file 3). The number of fetuses per group differed slightly because final selection of samples for analyses was dependent on mRNA integrity, as explained below. 
Table 2 Porcine specific primer sequences used to assess fetal apoptosis and hypoxia

\begin{tabular}{|c|c|c|c|c|c|c|}
\hline Pathway & Target & NCBI Gene ID & Forward primer & Reverse primer & $\operatorname{Tm}\left({ }^{\circ} \mathrm{C}\right)$ & Length (bp) \\
\hline \multirow[t]{6}{*}{ Apoptosis } & CASP3 & 397,244 & 5'-GTGGGATTGAGACGGACAGT-3' & 5'-TTCGCCAGGAATAGTAACCAG-3' & 60 & 114 \\
\hline & CASP7 & $100,156,777$ & 5'-TCGGTGCAAGACCCTTTTAG-3' & 5'-GCCTGGAACTGTGGAATAGG-3' & 60 & 178 \\
\hline & CASP8 & 595,105 & 5'-GGAACTGCTITTCCGAATGA-3' & 5'-AGCATGACCCTGTAGGCAGA-3' & 60 & 126 \\
\hline & CASP9 & $100,518,913$ & 5'-TCTGCCCACACCTAGTGACA-3' & 5'-ACAGCATTGGAGACCCTGAG-3' & 60 & 171 \\
\hline & RIPK1 & $100,524,751$ & 5'-ATCCTGTACGGCAACTCTGG-3' & 5'-GGTGGTGTTCTCGAAGATGG-3' & 60 & 147 \\
\hline & RIPK3 & $100,153,263$ & 5'-AATAGGCCCTCCTTCCAAGA-3' & $5^{\prime}-\mathrm{CTCACGGACAGACAACAAGC-3^{ \prime }}$ & 60 & 162 \\
\hline Infection & IDO1 & $100,519,877$ & 5'-GCTGTCAGAGGGTCTGCTCT-3' & 5'-TGAAGGAACTCCACCCACAG-3' & 60 & 139 \\
\hline \multirow[t]{5}{*}{ Hypoxia } & HIF1a & 396,696 & 5'-GGCAGCAATGACACAGAAAC-3' & 5'-CTGATTGAGTGCAGGGTCAG-3' & 59 & 180 \\
\hline & VEGFa & 397,157 & 5'-CAACATCGCCATGCAGATTA-3' & 5'-GCATTCACATTTGTTGTGCTG-3' & 60 & 91 \\
\hline & NOX1 & $100,739,822$ & 5'-TCCCTTTACCCTGACCTCTG-3' & 5'-TCCACCTCAATCCTTGGAAC-3' & 60 & 132 \\
\hline & NOS2 & 396,859 & $5^{\prime}$-CTGTGAGACGTTCGATGTCC-3' & 5'-GCTGCTGAGAGCTTTGTTGA-3' & 59 & 139 \\
\hline & LDHA & 407,245 & 5'-TTCACCCCCTAAGCTGTCAT-3' & 5'-TAAGCACTGTCCACCACCTG-3' & 60 & 178 \\
\hline
\end{tabular}

\section{mRNA extraction and CDNA library generation}

Under liquid nitrogen, the selected fetal tissues were individually ground and RNA extracted using a double precipitation method employing Trizol (Thermofisher Scientific, Carlsbad, Canada), followed by DNase (Thermofisher Scientific, Carlsbad, Canada) treatment. RNA purity was determined using nanodrop spectrophotometry (Thermofisher Scientific, Carlsbad, Canada) and a denaturing agarose gel electrophoresis was used to determine mRNA integrity [42]. Only high-quality samples with discrete $18 \mathrm{~S}$ and $28 \mathrm{~S}$ rRNA bands were further analyzed. A cDNA library was created using $2 \mu \mathrm{g}$ of RNA following instructions for the High-Capacity cDNA Reverse Transcription kit (Thermofisher Scientific, Carlsbad, Canada).

\section{$R T-q P C R$}

Genes of interest were selected based on their involvement in response to infection (IDO1), hypoxia (HIF-1 $\alpha$, VEGF $\alpha$, LDHA, NOS2, and NOX1) and apoptosis (CASP3, CASP7, CASP8, CASP9, RIPK1, and RIPK3). The primers were designed based on the Sus scrofa 11.1 genome assembly to match all transcript variants of the RefSeq mRNA sequences and positioned to span exonexon junctions, when possible (Table 1). Eleven housekeeping genes (RPL19, HPRT1, GAPDH, ACTB, HMBS, YWHAZ, IPO8, STX5, SDHA, PPIA, and TBP) previously designed [17] were tested in each tissue and the most stable ones were used for further analyses, as follow: brain - HPRT, IPO8, YWHAZ; heart - RPL19, SDHA, STX5; and thymus - RPL19, SDHA, STX5. All primers were tested and approved with efficiency over $90 \%$ and presenting a single peak melting curve. Samples were run in duplicate, each containing $20 \mathrm{ng}$ of cDNA, by real time PCR using the SsoFast EvaGreen Supermix (BioRad) and CFX qPCR system (BioRad), $95^{\circ} \mathrm{C}$ for 2 min followed by 40 cycles of $95^{\circ} \mathrm{C}$ for $10 \mathrm{~s}$ and individual primer set melt temperature (Table 2) for $45 \mathrm{~s}$.

\section{Statistical analyses}

The geometric mean of the most stable housekeeping genes in each tissue was used to normalize the expression data. Fold change of each gene of interest was calculated using the $2^{-\Delta \Delta \mathrm{Ct}}$ method and univariate non-parametric analysis (Kruskal Wallis followed by pairwise Wilcoxon rank sum test and Bonferroni correction) was performed to determine group differences within genes. All statistical analyses were performed in R [43], data visualization was conducted with the ggplot2 [44] package and observed statistical differences $(P<0.05)$ marked by unique superscripts. The strength of relationship between target genes fold changes and the MFI lesions was assessed using Spearman's rank correlation test as described above for "Experiment 1" using MFI lesion scores (unpublished data) based on the same scoring previously described [13].

\begin{abstract}
Abbreviations
PRRSV2: Porcine reproductive and respiratory syndrome virus 2; CTRL: Fetuses from control (non-inoculated) gilts; LVL: Low viral load fetuses (Experiment 1); UNINF: Uninfected fetuses from inoculated gilts (Experiment 2); HVLVIA: Viable high viral load fetuses; HVL-MEC: High viral load meconiumstained fetuses.; DPI: Days post infection; HIF1a: Hypoxia-inducible Factor 1 subunit alpha; IDO1: Indoleamine 2,3-Dioxygenase 1; VEGFa: Vascular endothelial growth factor A; LDHA: Lactate Dehydrogenase A; NOS2: Nitric Oxide Synthase 2; NOX1: NADPH Oxidase 1; CASP3: Caspase 3;

CASP7: Caspase 7; CASP8: Caspase 8; CASP9: Caspase 9; RIPK1: Receptorinteracting serine/threonine-protein kinase 1; RIPK3: Receptor-interacting serine/threonine-protein kinase 3
\end{abstract}

\section{Supplementary Information}

The online version contains supplementary material available at https://doi. org/10.1186/s12917-021-02883-0.

Additional file 1. TUNEL staining in three fetal tissues of uninfected control fetuses. Scant cells with TUNEL positive staining are observed at higher magnification of fetal thymus (B) and liver (D), but not in heart (F).

Additional file 2. Experiment 1 (21 DPI) PRRSV RNA concentration by fetal group. Viral load expressed in log (base 10) in fetal serum (left) and thymus (right) for each of the four phenotypical fetal groups: noninfected control (CTRL), PRRSV-infected low viral load viable (LVL), PRRSV- 
infected high viral load viable (HVL-VIA), PRRSV-infected high viral load meconium stained (VHL-MEC).

Additional file 3. Experiment 2 ( 12 DPI) PRRSV RNA concentration by fetal group. Viral load expressed in log (base 10) in fetal serum (left) and thymus (right) for each of the four phenotypical fetal groups in heart (A), brain (B), and thymus (C): non-infected control (CTRL), uninfected fetuses from inoculated dams (UNINF), PRRSV-infected high viral load viable (HVL-VIA), PRRSV-infected high viral load meconium stained (VHL-MEC) fetuses.

\section{Acknowledgements}

We express special acknowledgment to numerous personnel (technicians, graduate students, summer students, colleagues) who helped in the preparation and implementation of this study. Animal Care was contracted to VIDO-Intervac, Saskatoon. Necropsies were performed at the Prairie Diagnostic Services, Saskatoon

\section{Authors' contributions}

CM: experimental design, sample collection, tissue RNA extraction, primer design, RT-qPCR analyses, TUNEL data analysis, statistical analysis, manuscript preparation; FM: sample collection, TUNEL staining, imaging, and quantification; JAP, GH, SD, DM, JH: experimental design, sample collection; JAP: tissue RNA extraction, primer design; JH: principal investigator, project design and management, sample collection, financial management, statistical analysis, manuscript preparation. The authors read and approved the final manuscript.

\section{Funding}

This project was supported by Genome Canada (grant \#345169) and Genome Prairie (Saskatchewan Ministry of Agriculture; grant \#20150329), along with administrative support provided by Genome Alberta and the University of Saskatchewan. The funding agencies had no involvement in study design, implementation, analyses or interpretation of the results.

\section{Availability of data and materials}

The datasets analysed for Experiments 1 and 2 are available from the corresponding author on reasonable request.

\section{Declarations}

\section{Ethics approval}

This study was approved by the University of Saskatchewan Animal Research Ethics Board and adhered to the Canadian Council on Animal Care guidelines for humane animal use (Protocols 20110102 and 20160023). The infected pregnant gilts were closely monitored for clinical signs and a human intervention point checklist was established to monitor the gilts for critical conditions post-inoculation. It was not feasible to monitor fetal conditions after the viral inoculation, but fetal compromise death was expected to occur at the later time points. Gilts were euthanized with intravenous sodium pentobarbital overdose followed by cranial captive bolt and exsanguination. Fetuses were euthanized as humanely as possible given that pentobarbital sodium crosses the MFI rapidly and enters fetal circulation prior to the onset of hypoxia and asphyxia.

\section{Consent for publication}

not applicable.

\section{Competing interests}

The authors declare no conflicts of interest with respect to the research, authorship and/or publication of this article.

\section{Author details}

'Western College of Veterinary Medicine, Saskatoon, 52 Campus Dr, Saskatoon, Saskatchewan S7N 5B4, Canada. ${ }^{2}$ Department of Animal Science, Purdue University, West Lafayette, USA.
Received: 26 November 2020 Accepted: 14 April 2021

Published online: 01 May 2021

\section{References}

1. Holtkamp DJ, Kliebenstein JB, Neumann EJ, Zimmerman JJ, Rotto HF, Yoder TK, et al. Assessment of the economic impact of porcine reproductive and respiratory syndrome virus on United States pork producers. J Swine Heal Prod. 2013;21 (2):72-84

2. Mengeling WL, Lager KM, Vorwald AC. Temporal characterization of transplacental infection of porcine fetuses with porcine reproductive and respiratory syndrome virus. Am J Vet Res. 1994:55(10):1391-8.

3. Lager KM, Halbur PG. ERRADOGross and microscopic lesions in porcine fetuses infected with porcine reproductive and respiratory syndrome virus. J Vet Diagn Investig. 1996;8(1996):275-82.

4. Rossow KD, Laube KL, Goyal SM, Collins JE. Fetal microscopic lesions in porcine reproductive and respiratory syndrome virus-induced abortion. Vet Pathol. 1996;33(1):95-9.

5. Suleman M, Novakovic P, Malgarin CM, Detmer SE, Harding JCS, MacPhee DJ. Spatiotemporal immunofluorescent evaluation of porcine reproductive and respiratory syndrome virus transmission across the maternal-fetal interface. Pathog Dis. 2018;76(5):1-14

6. Malgarin CM, Nosach R, Novakovic P, Suleman M, Ladinig A, Detmer SESE, et al. Classification of fetal resilience to porcine reproductive and respiratory syndrome (PRRS) based on temporal viral load in late gestation maternal tissues and fetuses. Virus Res. 2019;260:151-62.

7. Ladinig A, Detmer SE, Clarke K, Ashley C, Rowland RR, Lunney JK, et al. Pathogenicity of three type 2 porcine reproductive and respiratory syndrome virus strains in experimentally inoculated pregnant gilts. Virus Res. 2015;203:24-35.

8. Novakovic P, Harding JCS, AI-Dissi AN, Ladinig A, Detmer SE. Pathologic evaluation of type 2 porcine reproductive and respiratory syndrome virus infection at the maternal-fetal interface of late gestation pregnant gilts. PLoS One. 2016:11(3):e0151198.

9. Karniychuk UU, Saha D, Geldhof M, Vanhee M, Cornillie P, Van den Broeck $W$, et al. Porcine reproductive and respiratory syndrome virus (PRRSV) causes apoptosis during its replication in fetal implantation sites. Microb Pathog. 2011:51(3):194-202.

10. Karniychuk UU, De Spiegelaere W, Nauwynck HJ. Porcine reproductive and respiratory syndrome virus infection is associated with an increased number of Sn-positive and CD8-positive cells in the maternal-fetal interface. Virus Res. 2013;176(1-2):285-91.

11. Ladinig A, Ashley C, Detmer SE, Wilkinson JM, Lunney JK, Plastow G, et al. Maternal and fetal predictors of fetal viral load and death in third trimester, type 2 porcine reproductive and respiratory syndrome virus infected pregnant gilts. Vet Res. 2015;46:107.

12. Novakovic P, Detmer SE, Suleman M, Malgarin CM, MacPhee DJ, Harding JCS. Histologic changes associated with placental separation in gilts infected with porcine reproductive and respiratory syndrome virus. Vet Pathol. 2018;55(4):521-30.

13. Novakovic P, Harding JC, Al-Dissi AN, Detmer SE. Type 2 porcine reproductive and respiratory syndrome virus infection increases apoptosis at the maternal-fetal interface in late gestation pregnant gilts. PLoS One. 2017; 12(3):e0173360.

14. Lager KM, Halbur PG, Invest JVD. Gross and microscopic lesions in porcine fetuses infected with porcine reproductive and respiratory syndrome virus. J Vet Diagn Investig. 1996;8(1996):275-82.

15. Danial NN, Korsmeyer SJ. Cell death: critical control points. Cell. 2004;116(2): 205-19.

16. Wilkinson JM, Bao H, Ladinig A, Hong L, Stothard P, Lunney JK, et al. Genome-wide analysis of the transcriptional response to porcine reproductive and respiratory syndrome virus infection at the maternal/fetal interface and in the fetus. BMC Genomics. 2016;17:383.

17. Alex Pasternak J, MacPhee DJ, Harding JCS. Fetal cytokine response to porcine reproductive and respiratory syndrome virus-2 infection. Cytokine. 2020;126:154883.

18. Pasternak JA, MacPhee DJ, Harding JCS. Maternal and fetal thyroid dysfunction following porcine reproductive and respiratory syndrome virus2 infection. Vet Res. 2020;51:1.

19. Van Goor A, Pasternak A, Walker K, Hong L, Malgarin C, MacPhee DJDJ, et al. Differential responses in placenta and fetal thymus at 12 days post infection 
elucidate mechanisms of viral level and fetal compromise following PRRSV2 infection. BMC Genomics. 2020;21(1):1-20.

20. Christianson WT, Joo HS. Porcine reproductive and respiratory syndrome: a review. Swine Heal Prod. 1994;2(2):10-28.

21. Craig RA. Diseases of swine, [internet]. Diseases of swine. New York: O. Judd company; 1906

22. Karniychuk UU, Nauwynck HJ. Quantitative changes of sialoadhesin and CD163 positive macrophages in the implantation sites and organs of porcine embryos/fetuses during gestation. Placenta. 2009;30(6):497-500.

23. Novakovic P, Harding JC, Ladinig A, Al-Dissi AN, MacPhee DJ, Detmer SE. Relationships of CD163 and CD169 positive cell numbers in the endometrium and fetal placenta with type 2 PRRSV RNA concentration in fetal thymus. Vet Res. 2016;47(1):76.

24. Karniychuk UU, Nauwynck HJ. Pathogenesis and prevention of placental and transplacental porcine reproductive and respiratory syndrome virus infection. Vet Res. 2013;44(1):95

25. Ladinig A, Wilkinson J, Ashley C, Detmer SE, Lunney JK, Plastow G, et al. Variation in fetal outcome, viral load and ORF5 sequence mutations in a large scale study of phenotypic responses to late gestation exposure to type 2 porcine reproductive and respiratory syndrome virus. PLoS One. 2014;9(4):e96104.

26. Dhuriya YK, Sharma D. Necroptosis: a regulated inflammatory mode of cell death. J Neuroinflammation. 2018;15(1):1-9.

27. Rowland RR. The interaction between PRRSV and the late gestation pig fetus. Virus Res. 2010;154(1-2):114-22.

28. Cheon D-S, Chae C. Comparison of virus isolation, reverse transcriptionpolymerase chain reaction, immunohistochemistry, and in situ hybridization for the detection of porcine reproductive and respiratory syndrome virus from naturally aborted fetuses and stillborn piglets. J Vet Diagn Investig. 2000;12(6):582-7.

29. Cheon DS, Chae C. Distribution of porcine reproductive and respiratory syndrome virus in stillborn and liveborn piglets from experimentally infected sows. J Comp Pathol. 2001;124(4):231-7.

30. Amadori M, Razzuoli E. Immune control of PRRS: lessons to be learned and possible ways forward. Front Vet Sci. 2014;14:1.

31. Schönenberger MJ. Hypoxia signaling pathways: modulators of oxygenrelated organelles. Front Cell Dev Biol. 2015;3:42.

32. Lee JW, Ko J, Ju C, Eltzschig HK. Hypoxia signaling in human diseases and therapeutic targets. Exp Mol Med. 2019;51(6):68.

33. Shimizu S, Equchi Y, Kosaka H, Kamiike W, Matsuda H, Tsujimoto Y. Prevention of hypoxia-induced cell death by BCl-2 and BCl-xL. Nature. 1995; 374(6525):811-3.

34. Goyal P, Weissmann N, Grimminger F, Hegel C, Bader L, Rose F, et al. Upregulation of $\mathrm{NAD}(\mathrm{P}) \mathrm{H}$ oxidase 1 in hypoxia activates hypoxia-inducible factor 1 via increase in reactive oxygen species. Free Radic Biol Med. 2004; 36(10):1279-88.

35. Forstermann U, Sessa WC. Nitric oxide synthases: regulation and function. Eur Heart J. 2012;33(7):829-37.

36. Hale LP, Braun RD, Gwinn WM, Greer PK, Dewhirst MW. Hypoxia in the thymus: Role of oxygen tension in thymocyte survival. Am J Physiol Heart Circ Physiol. 2002;282(451-4):1467-77.

37. Ohta A, Diwanji R, Kini R, Subramanian M, Ohta A, Sitkovsky M. In vivo T cell activation in lymphoid tissues is inhibited in the oxygen-poor microenvironment. Front Immunol. 2011;2:1-10.

38. Richardson LA. Understanding disease tolerance and resilience. PLoS Biol. 2016;14(7):e1002513

39. Malgarin CM, MacPhee DJ, Harding JCS. Fetal metabolomic alterations following porcine reproductive and respiratory syndrome virus infection. Front Mol Biosci. 2020;11:7.

40. Zhang Q, Yoo D. PRRS virus receptors and their role for pathogenesis. Vet Microbiol. 2015;177(3-4):229-41.

41. Akoglu H. User's guide to correlation coefficients. Turkish J Emerg Med. 2018;18(3):91-3.

42. Kent-Dennis C, Pasternak A, Plaizier JC, Penner GB. Potential for a localized immune response by the ruminal epithelium in nonpregnant heifers following a short-term subacute ruminal acidosis challenge. J Dairy Sci. 2019;102(8):7556-69.

43. Team RC. R: a language and environment for statistical computing. [internet]. Vienna: R Foundation for Statistical Computing; 2020.

44. Wickham H. ggplot2: Elegant Graphics for Data Analysis: Springer-Verlag New York; 2016

\section{Publisher's Note}

Springer Nature remains neutral with regard to jurisdictional claims in published maps and institutional affiliations.

\section{Ready to submit your research? Choose BMC and benefit from:}

- fast, convenient online submission

- thorough peer review by experienced researchers in your field

- rapid publication on acceptance

- support for research data, including large and complex data types

- gold Open Access which fosters wider collaboration and increased citations

- maximum visibility for your research: over $100 \mathrm{M}$ website views per year

At BMC, research is always in progress.

Learn more biomedcentral.com/submissions 